\title{
BIOAVAILABILITY ENHANCDEMENT OF POORLY SOLUBLE DRUGS BY SMEDDS: A REVIEW
}

\author{
Jaiswal Parul*, Aggarwal Geeta, Harikumar SL, Kaur Amanpreet \\ Rayat and Bahra Institute of Phamacy, Sahauran, Kharar, District Mohali, Punjab, India-140104 \\ *Corresponding Author's E-mail: paruljaiswal9@gmail.com, Contact No: +91-9872711223
}

Received 10 Dec 2012; Review Completed 01 Jan 2013; Accepted 01 Jan 2013, Available online 15 Jan 2013

\begin{abstract}
Oral route has always been the favorite route of drug administration in many diseases and till today it is the first way investigated in the development of new dosage forms. The major problem in oral drug formulations is low and erratic bioavailability, which mainly results from poor aqueous solubility, thereby pretense problems in their formulation. More than $40 \%$ of potential drug products suffer from poor water solubility. For the therapeutic delivery of lipophilic active moieties (BCS class II drugs), lipid based formulations are inviting increasing attention. Currently a number of technologies are available to deal with the poor solubility, dissolution rate and bioavailability of insoluble drugs such as micronization, solid dispersions or cyclodextrin complex formation and different technologies of drug delivery systems. One of the promising techniques is Self-Micro Emulsifying Drug Delivery Systems (SMEDDS). Self emulsifying drug delivery system has gained more attention due to enhanced oral bio-availability enabling reduction in dose, more consistent temporal profiles of drug absorption, selective targeting of drug(s) toward specific absorption window in GIT, and protection of drug(s) from the unreceptive environment in gut. This article gives a complete overview of SMEDDS as a promising approach to effectively deal with the problem of poorly soluble molecules.

Keywords: SMEDDS, surfactant, oil, co-surfactant, bioavailability
\end{abstract}

\section{INTRODUCTION}

The oral delivery of lipophilic drugs presents a major challenge because of the low aqueous solubility. Lipidbased formulations have been shown to enhance the bioavailability of drugs administered orally ${ }^{1,2,3,4}$. Wide availability of lipidic excipients with specific characteristics offers flexibility of application with respect to improving the bioavailability of poorly water-soluble drugs and manipulating their release profiles ${ }^{5}$. Selfmicroemulsifying drug delivery system(SMEDDS) are defined as isotropic mixtures of natural or synthetic oils, solid or liquid surfactants, or alternatively, one or more hydrophilic solvents and co-solvents/surfactants that have a unique ability of forming fine oil-in-water $(\mathrm{o} / \mathrm{w})$ micro emulsions upon mild agitation followed by dilution in aqueous media, such as GI fluids ${ }^{6}$.

The self emulsification process is specific to the particular pair of oil and surfactant, surfactant concentration, oil/surfactant ratio, and the temperature at which self-emulsification occurs ${ }^{7,8,9}$. After self dispersion, the drug is rapidly distributed throughout the gastrointestinal tract as fine droplets. The large surface area enhances the dissolution. The emulsion globules are further solubilized in the gastrointestinal tract by bile fluids. The presence of surfactant causes enhanced absorption due to membrane induced permeation changes. The droplets formed are either positively charged or negatively charged. As the mucosal lining is negatively charged it was observed that positively charged particles penetrated deeper into the ileum ${ }^{10}$. A cationic emulsion has greater bioavailability than an anionic emulsion ${ }^{11,}{ }^{12}$. Self-Emulsifying Drug Delivery Systems (SEDDS) formed using surfactants of
HLB $<12$ and Self-Micro Emulsifying Drug Delivery Systems (SMEDDS) formed with surfactants of HLB > 12 . Both SEDDS and SMEDDS are stable preparations and improve the dissolution of the drug due to increased surface area on dispersion. The emulsified form itself is readily absorbable which ensures a rapid transport of poorly soluble drugs into the blood. Many researchers have reported applications of SEDDS for delivering and targeting lipophilic drugs e.g., coenzyme Q10 ${ }^{13}$, vitamin $\mathrm{E}^{14}$, halofantrine ${ }^{15}$ and cyclosporine $\mathrm{A}^{16}$. Upon per oral administration, these systems form fine emulsions (or micro-emulsions) in gastro-intestinal tract (GIT) with mild agitation provided by gastric mobility. Khoo et al (1988) demonstrated enhanced drug absorption when using long chain triglycerides (LCT) compared with medium chain triglycerides (MCT) in the SMEDDS formulations ${ }^{15}$. These findings are attributed to maximal stimulation of lymphatic transport by the LCT. Studies indicated that the rate of intestinal absorption of N-LCT was similar to that of the other Pharmacopoeial vegetable oils such as, sunflower, sesame and groundnut oil ${ }^{17}$; suggesting that the N-LCT is acceptable for human consumption and pharmaceutical applications. The N-LCT offers many other advantages such as, easy availability in large quantities from natural source, toxicologically safe, completely biocompatible and cost effective replacement for commercial triglycerides and modified oils.

\section{NEED OF SMEDDS}

Oral delivery of poorly water-soluble compounds is to predissolve the compound in a suitable solvent and fill the formulation into capsules. The main benefit of this ISSN: 2250-1177 
approach is that pre-dissolving the compound overcomes the initial rate limiting step of particulate dissolution in the aqueous environment within the GI tract. However, a potential problem is that the drug may precipitate out of solution when the formulation disperses in the GI tract, particularly if a hydrophilic solvent is used (e.g. polyethylene glycol). If the drug can be dissolved in a lipid vehicle there is less potential for precipitation on dilution in the GI tract, as partitioning kinetics will favor the drug remaining in the lipid droplets. Another strategy for poorly soluble drugs is to formulate in a solid solution using a water-soluble polymer to aid solubility of the drug compound. For example, polyvinylpyrrolidone (PVP) and polyethylene glycol (PEG 6000) have been used for preparing solid solutions with poorly soluble drugs. One potential problem with this type of formulation is that the drug may favor a more thermodynamically stable state, which can result in the compound crystallizing in the polymer matrix. Therefore the physical stability of such formulations needs to be assessed using techniques such as differential scanning calorimetry or X-ray crystallography ${ }^{18}$. Self-micro emulsifying drug delivery system is a novel approach and is being extensively used to enhance the solubility and bioavailability of poorly water soluble drugs. In addition to this, the formulated SMEDDS will also prevent the drug from hostile gastric environment which will further help in better systemic absorption.

\section{ADVANTAGES OF SMEDDS}

\section{- Improvement in oral bioavailability}

The ability of SMEDDS to present the drug to GIT in solubilised and micro emulsified form (globule size between 1-100 $\mathrm{nm}$ ) and subsequent increase in specific surface area enable more efficient drug transport through the intestinal aqueous boundary layer and through the absorptive brush border membrane leading to improved bioavailability. E.g. In case of halofantrine approximately 6-8 fold increase in bioavailability of drug was reported in comparison to tablet formulation ${ }^{15}$.

\section{- $\quad$ Ease of manufacture and scale-up}

SMEDDS require very simple and economical manufacturing facilities like simple mixer with agitator and volumetric liquid filling equipment for large-scale manufacturing. This explains the interest of industry in the SMEDDS.

- Reduction in inter-subject and intra-subject variability and food effects

There are several drugs which show large inter-subject and intra-subject variation in absorption leading to decreased performance of drug and patient non-compliance. Food is a major factor affecting the therapeutic performance of the drug in the body. SMEDDS are a boon for such drugs. Several research papers specifying that, the performance of SMEDDS is independent of food and, SMEDDS offer reproducibility of plasma profile are available ${ }^{18}$.

- Ability to deliver peptides that are prone to enzymatic hydrolysis in GIT
SMEDDS are superior as compared to the other drug delivery systems due to their ability to deliver macromolecules like peptides, hormones, enzyme substrates and inhibitors and their ability to offer protection from enzymatic hydrolysis. The intestinal hydrolysis of prodrug by cholinesterase can be protected if Polysorbate 20 is emulsifier in micro emulsion formulation $^{19}$. These systems are formed spontaneously without aid of energy or heating thus suitable for thermolabile drugs such as peptides ${ }^{20}$.

\section{- No influence of lipid digestion process}

Unlike the other lipid-based drug delivery systems, the performance of SMEDDS is not influenced by the lipolysis, emulsification by the bile salts, action of pancreatic lipases and mixed micelle formation.

\section{- Increased drug loading capacity}

As the solubility of poorly water soluble drugs with intermediate partition coefficient $(2<\log \mathrm{P}>4)$ are typically low in natural lipids and much greater in amphilic surfactants, co surfactants and co-solvents.

- In SMEDDS, the lipid matrix interacts readily with water, forming a fine particulate oil-

in-water $(\mathrm{o} / \mathrm{w})$ emulsion. The emulsion droplets will deliver the drug to the gastrointestinal mucosa in the dissolved state readily accessible for absorption. Therefore increase in AUC i.e. bioavailability and C max is observed with many drugs when presented in SMEDDS ${ }^{21}$.

- Fine oil droplets empty rapidly from the stomach and promote wide distribution of drug throughout the intestinal tract and thereby minimizing irritation frequently encountered with extended contact of drugs and gut wall ${ }^{22}$.

- When polymer is incorporated in composition of SMEDDS it gives prolonged release of

medicament ${ }^{23}$.

- $\quad$ SMEDDS present drugs in a small droplet size and well-proportioned distribution and increase the dissolution and permeability. Furthermore, because drugs can be loaded in the inner phase and delivered to the lymphatic system, can bypass first pass metabolism. Thus SMEDDS reduce the presystemic clearance in the GI mucosa and hepatic first-pass metabolism.

- Selective targeting of $\operatorname{drug}(\mathrm{s})$ toward specific absorption window in GIT $^{21}$.

- Protection of $\operatorname{drug}(\mathrm{s})$ from the hostile environment in gut $^{22}$.

- Protective of sensitive drug substances.

- Liquid or solid dosage forms

\section{ADVANTAGES OF SMEDDS OVER EMULSION}

- SMEDDS not only offer the same advantages of emulsions of facilitating the solubility of

hydrophobic drugs, but also overcomes the drawback of the layering of emulsions after sitting for a long 
time. It can be easily stored since it belongs to a thermodynamics stable system.

- Microemulsions formed by the SMEDDS exhibit good thermodynamics stability and

optical transparency. Droplets of microemulsion formed by the SMEDDS generally ranges between 2 and $100 \mathrm{~nm}$. Since the particle size is small, the total surface area for absorption and dispersion is significantly larger than that of solid dosage form and it can easily penetrate the gastrointestinal tract and be absorbed. The bioavailability of the drug is therefore improved.

- $\quad$ SMEDDS offer numerous delivery options like can be filled in hard gelatin capsules or soft gelatin capsules or can be formulated into tablets whereas emulsions can only be given as oral solutions.

- Emulsion cannot be autoclaved as they have phase inversion temperature, while SMEDDS can be autoclaved $^{24}$.

\section{DISADVANTAGES OF SMEDDS ${ }^{25}$}

- Lack of good predicative in vitro models for assessment of the formulations.

- This in vitro model needs further development and validation before its strength can be evaluated.

- Further development will be based on in vitro - in vivo correlations and therefore different prototype lipid based formulations needs to be developed and tested in vivo in a suitable animal model.

- Another is chemical instabilities of drugs and high surfactant concentrations in formulations (approximately 30-60\%) which irritate GIT.

- Moreover, volatile co solvents in the conventional self-microemulsifying formulations are known to migrate into the shells of soft or hard gelatin capsules, resulting in the precipitation of the lipophilic drugs.

- The precipitation tendency of the drug on dilution may be higher due to the dilution effect of the hydrophilic solvent.

\section{APPLICATIONS OF SMEDDS}

- SUPERSATURABLE SMEDDS (S-SMEDDS): SSMEDDS formulations have been designed and developed to reduce the surfactant side effects and achieve rapid absorption of poorly soluble drugs ${ }^{26}$.

- SOLID SMEDDS: SMEDDS are normally prepared as liquid dosage forms that can be administrated in soft gelatin capsules, which have some disadvantages especially in the manufacturing process. An alternative method is the incorporation of liquid self emulsifying ingredients into a powder in order to create a solid dosage form (tablets, capsules). A pellet formulation of progesterone in SMEDDS has been prepared by the process of extrusion spheronization to provide a good in vitro drug release $(100 \%$ within 30 min, $\mathrm{T} 50 \%$ at $13 \mathrm{~min}$ ). The same dose of progesterone (16 $\mathrm{mg}$ ) in pellets and in the SEDDS liquid formulation resulted in similar AUC, C max and T max values ${ }^{27}$. Applications of SMEEDS are enlisted in Table 1.

\section{FORMULATION COMPONENTS OF SMEDDS:}

- Drug

- Oil

- Surfactant

- Co-surfactant

- Co-solvent

- Consistency Builder

- Enzyme Inhibitors

- Adsorbents/solidifying agents

- Polymers

- Other Components

Oils: The oil represents one of the most important excipients in the SMEDDS formulation not only because it can solubilize the required dose of the lipophilic drug or facilitate self emulsification but also and mainly because it can increase the fraction of lipophilic drug transported via the intestinal lymphatic system, thereby increasing absorption from the GI tract depending on the molecular nature of the triglyceride ${ }^{29}$. Both long and medium chain triglyceride (LCT and MCT) oils with different degrees of saturation have been used for the design of selfemulsifying formulations. Furthermore, edible oils which could represent the logical and preferred lipid excipient choice for the development of SMEDDS are not frequently selected due to their poor ability to dissolve large amounts of lipophilic drugs. Modified or hydrolyzed vegetable oils have been widely used since these excipients form good emulsification systems with a large number of surfactants approved for oral administration and exhibit better drug solubility properties. They offer formulative and physiological advantages and their degradation products resemble the natural end products of intestinal digestion. Novel semisynthetic medium chain derivatives, which can be defined as amphiphilic compounds with surfactant properties, are progressively and effectively replacing the regular medium chain triglyceride oils in the SMEDDS ${ }^{25}$. This is in accordance with findings of Deckelbaum (1990) showing that MCT is more soluble and have a higher mobility in the lipid/water interfaces than LCT associated with a more rapid hydrolysis of MCT. Almond oil, Canola oil, Coconut oil, Coconut oil, Corn oil, Cottonseed oil, Olive oil, Peanut oil, Safflower oil, Sesame oil, Shark liver oil, Soyabean oil, Wheat germ oil etc are the commercially available triglycerides ${ }^{30}$. 
Table: 1 Applications of SMEDDS reported in literature ${ }^{28}$

\begin{tabular}{|c|c|c|c|c|c|}
\hline $\begin{array}{l}\text { Type Of } \\
\text { Delivery } \\
\text { System }\end{array}$ & DRUG & OIL & Surfactant & $\begin{array}{l}\text { Co-solvent / } \\
\text { Cosurfactant }\end{array}$ & SIGNIFICANCE \\
\hline SMEDDS & Atorvastatin & $\begin{array}{l}\text { Labrafil, Estol } \\
\text { and Isopropyl } \\
\text { myristate }\end{array}$ & $\begin{array}{l}\text { Cremophore El, } \\
\text { Cremophor RH } \\
40\end{array}$ & $\begin{array}{l}\text { Propylene } \\
\text { glycol, PEG } \\
400 \text { and } \\
\text { Transcutol }\end{array}$ & $\begin{array}{l}\text { Improves solubility bioavailability and } \\
\text { permeability via the mucous membrane. Oral } \\
\text { bioavailability increased nearly } 1.5 \text { times. }\end{array}$ \\
\hline SMEDDS & Simvastatin & Caproyl 90 & Cremophore EL & Carbitol & $\begin{array}{l}\text { Release rate was higher than conventional } \\
\text { tablets. The oral bioavailability of SMEDDS is } \\
\text { about 1.5-fold higher than conventional } \\
\text { tablets. }\end{array}$ \\
\hline SMEDDS & Seocalcitol & $\begin{array}{l}\text { Viscoleo } \\
\text { (MCT), } \\
\text { Sesame oil } \\
(\text { LCT })\end{array}$ & $\begin{array}{l}\text { Cremophore } \\
\text { RH40 }\end{array}$ & Akoline & $\begin{array}{l}\text { No improvement in bioavailability. After three } \\
\text { months of storage at accelerated conditions } \\
\left(40^{\circ} \mathrm{C} / 75 \% \mathrm{RH}\right) \text {, a decrease in concentration } \\
\text { of } 10-11 \% \text { was found. Simple lipid solutions } \\
\text { are better choice compared with the developed } \\
\text { SMEDDS due to a slightly higher } \\
\text { biovailability and better chemical stability. }\end{array}$ \\
\hline SEDDS & Ontazolast & $\begin{array}{l}\text { mixture of } \\
\text { mono-and } \\
\text { diglyceri-des } \\
\text { of oleic acid }\end{array}$ & $\begin{array}{l}\text { Solid,Polyglyc- } \\
\text { olyzed mono-di } \\
\text { and triglycerides, } \\
\text { Tween } 80\end{array}$ & & Enhanced bioavailability by 7.5 drug content. \\
\hline SMEDDS & Silmyrin & Ethyl linoleate & Tween 80 & Ethyl alcohol & $\begin{array}{l}\text { Release was limited, incomplete and typical of } \\
\text { sustained characteristics. Relative } \\
\text { bioavailability dramatically enhanced in an } \\
\text { average of } 1.88 \text { and } 48.82 \text { fold that of } \\
\text { silymarin PEG } 400 \text { solution and suspension } \\
\text { respectively. }\end{array}$ \\
\hline $\begin{array}{l}\text { Self } \\
\text { Emulsifying } \\
\text { Pellets }\end{array}$ & $\begin{array}{l}\text { Methyl and } \\
\text { propyl } \\
\text { parabens }\end{array}$ & $\begin{array}{l}\text { Mono \& } \\
\text { diglycerides of } \\
\text { capric and } \\
\text { caprylic acids }\end{array}$ & Tween 80 & & $\begin{array}{l}\text { Improved rate of drug release from the pellets. } \\
\text { By applying a water insoluble polymer } \\
\text { containing a water soluble plastisizer it } \\
\text { reduces the rate of drug release }\end{array}$ \\
\hline SEDDS & Ketoprufen & Captex 200 & Tween 80 & Capmul MCM & $\begin{array}{l}\text { Silicon dioxide was used as gelling agent. As } \\
\text { the concentration of silicon dioxide increases, } \\
\text { it causes an increase in the droplet size and } \\
\text { slows the drug diffusion. }\end{array}$ \\
\hline SEDDS & Crvedilol & Labrasol & $\begin{array}{l}\text { Labrafil M } \\
\text { 1944CS } \\
\end{array}$ & Transcutol P & Improves the oral bioavailability of upto $413 \%$ \\
\hline SEDDS & Itraconazole & $\begin{array}{l}\text { Tocopherol } \\
\text { acetate }\end{array}$ & Pluronic L64 & Transcutol & $\begin{array}{l}\text { Greatly enhanced bioavailability without the } \\
\text { influence of food. }\end{array}$ \\
\hline SNEDDS & $\begin{array}{l}\text { Cefpodoxim- } \\
\text { e proxetil } \\
\text { (CFP) }\end{array}$ & Capryol 90 & $\begin{array}{l}\text { Cremophor } \\
\text { EL, Solutol } \\
\text { HS }\end{array}$ & Akoline & $\begin{array}{l}\text { High dose of CFP }(130 \mathrm{mg}) \text { exhibited rapid } \\
\text { release independent of } \mathrm{pH} \text { of dissolution } \\
\text { media. }\end{array}$ \\
\hline
\end{tabular}

Surfactant: Surfactant molecules may be classified based on the nature of the hydrophilic group within the molecule. The four main groups of surfactants are defined as follows:

Anionic Surfactants, where the hydrophilic group carries a negative charge such as carboxyl (RCOO-),sulphonate (RSO3-) or sulphate (ROSO3-). Examples: Potassium laurate, sodium lauryl sulphate.

Cationic surfactants, where the hydrophilic group carries a positive charge. Example: quaternary ammonium halide.

Ampholytic surfactants (also called zwitterionic surfactants) contain both a negative and a positive charge. Example: sulfobetaines.

Nonionic surfactants, where the hydrophilic group carries no charge but derives its water solubility from highly polar groups such as hydroxyl or polyoxyethylene (OCH2CH2O). Examples: Sorbitan esters (Spans), polysorbates (Tweens).
Nonionic surfactants with high hydrophilic lipophilic balance (HLB) values are used in formulation of SMEDDS. The usual surfactant strength ranges between $30-60 \% \mathrm{w} / \mathrm{w}$ of the formulation in order to form a stable SMEDDS. Surfactants having a high HLB and hydrophilicity assist the immediate formation of $\mathrm{o} / \mathrm{w}$ droplets and/or rapid spreading of the formulation in the aqueous media. Surfactants are amphiphilic in nature and they can dissolve or solubilize relatively high amount of hydrophobic drug compounds ${ }^{31}$. Safety is a major determining factor in choosing a surfactant. Emulsifiers of natural origin are preferred since they are considered to be safer than the synthetic surfactants ${ }^{29}$. However, these surfactants have a limited self emulsification capacity. Non-ionic surfactants are less toxic than ionic surfactants but they may lead to reversible changes in the permeability of the intestinal lumen ${ }^{32}$. Large amounts of surfactants may cause GI irritation. There is a relationship between the droplet size and the concentration of the surfactant being used. In some cases, increasing the surfactant ISSN: 2250-1177 CODEN (USA): JDDTAO 
concentration could lead to droplets with smaller mean droplet size, this could be explained by the stabilization of the oil droplets as a result of the localization of the surfactant molecules at the oil-water interface ${ }^{33}$. On the other hand, in some cases the mean droplet size may increase with increasing surfactant concentrations ${ }^{34}$. This phenomenon could be attributed to the interfacial disruption elicited by enhanced water penetration into the oil droplets mediated by the increased surfactant concentration and leading to ejection of oil droplets into the aqueous phase ${ }^{35}$. The surfactants used in these formulations are known to improve the bioavailability by various mechanisms including: improved drug dissolution, increased intestinal epithelial permeability, increased tight junction permeability and decreased/inhibited pglycoprotein drug efflux.

Co-surfactants: Generally co-surfactant of HLB value 1014 is used with surfactant together to decrease the interfacial tension to a very small even transient negative value. At this value the interface would expand to form fine dispersed droplets, and subsequently adsorb more surfactant until their bulk condition is depleted enough to make interfacial tension positive again. This process is known as spontaneous emulsification forms the microemulsion. The selection of co-surfactant and surfactant is crucial not only to form the formation of microemulsion, but also to solubilization in microemulsions. Other variables such as the chemical nature of oil, salinity and temperature are also expected to influence the curvature of the interfacial film. Organic solvents like ethanol, propylene glycol, polyethylene glycol suitable for oral administration may help to dissolve large amounts of either the hydrophilic surfactant or the drug in the lipid base and can act as cosurfactant in the microemulsion systems. Literature has been described alcohol and propylene glycol free self emulsifying microemulsions ${ }^{21}{ }^{36}$. The drugs in the alcohol free formulations may exhibit limited solubility. Hydrophilic co-surfactants are preferably alcohols of intermediate chain length such as hexanol, pentanol and octanol, which are known to reduce the oil/water interface and allow the spontaneous formulation of microemulsion. Examples of various surfactants, co-surfactants and cosolvents used in

Commercial formulations are enlisted in Table 2.

Co-solvents: Organic solvents and additional compounds suitable for oral administration are used in SMEDDS to enhance the solubility of therapeutic agent or triglyceride in the composition ${ }^{37}$. Examples;

- Alcohols and Polyols: Such as ethanol, isopropranol, butanol, benzyl alcohol, ethylene glycol, propylene glycol, butanediols and isomers thereof, glycerol, pentaerythritol, sorbitol, mannitol, transcutol, dimethyl isosorbide, propylene glycol, polypropylene glycol, hydroxyprpyl methyl cellulose and other cellulosic polymers, cyclodextrins and its derivatives.

- Esters of propylene glycols having average molecular weight of about 200 to 6000 such as tetrahydrofuryl alcohol, PEG ether (glycofural) or methoxy PEG.
- Amides such as 2-pyrrolidone, 2-piperidone, caprolactam, N-alkylpyrrolidone, Nhydroxyalkylepyrrolidone, N-alkylpiperidone, Nalkylcaprolactam, dimethylacetamide an polyvinyl pyrrolidone.

- $\quad$ Esters, such as ethyl propionate, tributyl citrate, acetyl triethyle citrate, acetyl tributyl citrate, ethylene oleate, ethyl caprylate, ethyl butyrate, triacetin, propylene glycol monoacetate, propylene glycol diacetate, $\square$ caprolactone, $\square$-valerolactone, $\square$-butyrolactone.

Consistency builder: Tragacanth, cetyl alcohol, stearic acid or beeswax can be added to alter the consistency of the emulsion ${ }^{23}$.

Enzyme inhibitors: If the therapeutic agent is subject to enzymatic degradation, enzyme inhibitors can be added to the composition of SMEDDS. Enzyme inhibitors ${ }^{37}$ are;

1) Inhibitors that are not based on amino acids. E.g. Paminobenzamidine, FK-448, Cosmostat mesylate, Sodium glycocolate.

2) Amino acids and modified amino acids e.g. aminoboronine derivatives and $\mathrm{n}$-acetylcysteine.

3) Peptides and modified peptides e.g. Bacitracin, antipain, leupeptin, amastatin.

4) Polypeptide protease inhibitors e.g. Apratinin, BowmanBirk inhibitor, Soyabeen trypsin inhibitor, Chicken egg white trypsin inihibitor.

5) Complexing agent e.g. EDTA, EGTA, 1, 10 Phenanthroline, Hydroxychinoline.

Adsorbants/solidifying agents: This process requires very high amounts of solidifying aids such as cellulose, lactose and silicates. Nazzal et al formulated eutectic based solid self-nanoemulsifying drug delivery systems (SNEDDS) using interaction between ubiquinone and oils that formed wax-like paste, which was further mixed with copolyvidone, maltodextrin and microcrystalline cellulose to obtain tablets ${ }^{40}$. Solid self-emulsifying system comprising goat fat and Tween 65 were formulated for delivery of diclofenac ${ }^{41}$. But the goat fat, used as an oil phase, has very limited solvent capacity and the tablets were produced using plastic molds without application of compression force. With lactose and microcrystalline cellulose as solidifying agents, solid self-microemulsifying system has been formulated by using an extrusion spheronization technique. It is reported that transformation of self-emulsifying system in solid dosage forms by addition of large amounts of solidifying excipients ${ }^{42}$. But in all these studies, to obtain solids with suitable processing properties, the required ratio of solidifying excipients to selfemulsifying drug delivery system (SEDDS) was very high, and it seems to be practically infeasible for drugs having limited solubility in oil phase. Gelled selfemulsifying drug delivery system of ketoprofen has been formulated to serve as an intermediate for further transformation into semisolid or solid dosage forms ${ }^{43}$. Recently liquid self-emulsifying system of loratadine transformed into solid dosage form by using porous polystyrene beads as solidifier. But in this study the ratio of solidifying carrier to self-emulsifying system is low ${ }^{44}$. 
Table: 2 Example of surfactants, co-surfactant, and co-solvent used in commercial formulations ${ }^{36}$

\begin{tabular}{|c|c|}
\hline Excipient Name (commercial name) & $\begin{array}{l}\text { Examples of commercial products in which it has been } \\
\text { used }\end{array}$ \\
\hline \multicolumn{2}{|l|}{ Surfactants/co-surfactants } \\
\hline Polysorbate 20 (Tween 20) & Targretin soft gelatin capsule \\
\hline Polysorbate 80 (Tween 80$)$ & Gengraf hard gelatin capsule \\
\hline Sorbitan monooleate (Span 80) & Gengraf hard gelatin capsule \\
\hline Polyoxy-35-castor oil(Cremophor RH40) & Gengraf hard gelatin capsule, Ritonavir soft gelatin capsule \\
\hline Polyoxy-40- hydrogenated castor oil (Cremophor RH40) & Nerol soft gelatin capsule, Ritonavir oral solution \\
\hline Polyoxyethylated glycerides (Labrafil M 2125 Cs) & Sandimmune soft gelatin capsules \\
\hline Polyoxyethlated oleic glycerides（Labrafil M1944 Cs) & Sandimmune oral solution \\
\hline $\begin{array}{l}\text { D-alpha Tocopheryl polyethylene glycol } 1000 \text { succinate } \\
\text { (TPGS) }\end{array}$ & Agenerage Soft gelatin capsule, Agenarage oral solution \\
\hline \multicolumn{2}{|l|}{ Co-solvents } \\
\hline Ethanol & Nerol soft gelatin Capsule, Nerol Oral Solution, Gengraf \\
\hline Glycerin & $\begin{array}{l}\text { hard gelatin Capsule, Sandimmune soft gelatin Capsule, } \\
\text { Sandimmune oral solution }\end{array}$ \\
\hline Polypylene glycol & $\begin{array}{l}\text { Nerol soft gelatin Capsule, Sandimmune soft gelatin } \\
\text { Capsules }\end{array}$ \\
\hline Polyethylene glycol & $\begin{array}{l}\text { Nerol soft gelatin Capsule, Nerol Oral Solution, Lamprene } \\
\text { soft gelatin capsule, Agenerage Oral solution, Gengraf } \\
\text { hard gelatin capsule }\end{array}$ \\
\hline \multicolumn{2}{|l|}{ Lipid ingredients } \\
\hline Corn oilmono,di,,tri-glycerides & $\begin{array}{l}\text { Targretin soft gelatin capsule, Gengraf hard gelatin } \\
\text { capsule, Agenerase soft capsule, Agenerase oral solution }\end{array}$ \\
\hline DL-alpha-Tocopherol & Nerol soft gelatin Capsule, Nerol Oral Solution \\
\hline $\begin{array}{l}\text { Fractionated triglyceride of coconut oil (medium-chain } \\
\text { triglyceride) }\end{array}$ & Nerol Oral Solution, Fortavase soft gelatin capsule \\
\hline $\begin{array}{l}\text { Fractionated triglyceride of palm seed oil (medium-chain } \\
\text { triglyceride) }\end{array}$ & Rocaltrol soft gelatin capsule, Hectrol soft gelatin capsule \\
\hline Mixture of mono-and di-glycerides of caprylic/capric acid & Rocatrol oral solution \\
\hline Medium chain mono-and di-glycerides & Avodat soft gelatin capsule \\
\hline Corn oil & Fortavase soft gelatin capsule \\
\hline Olive oil & Sandimmune soft gelatin capsule, Depakene capsule \\
\hline Oleic acid & Sandimmune oral solution \\
\hline Sesame oil & $\begin{array}{l}\text { Ritonavir soft gelatin capsule, Norvir soft gelatin capsule } \\
\text { Marinol soft gelatin capsule }\end{array}$ \\
\hline Hydrogenated soyabean oil & $\begin{array}{l}\text { Accutane soft gelatin capsule, Vesanoid soft gelatin } \\
\text { capsule }\end{array}$ \\
\hline Hydrogenated vegetable oils & $\begin{array}{l}\text { Accutane soft gelatin capsule, Vesanoid soft gelatin } \\
\text { capsule }\end{array}$ \\
\hline Soyabean oil & Accutane soft gelatin capsule \\
\hline Peanut oil & Prometrium soft gelatin capsule \\
\hline Beeswax & Vesanoid soft gelatin capsule \\
\hline
\end{tabular}


Polymers: Inert polymer matrix representing from 5 to $40 \%$ of composition relative to the weight, which is not ionizable at physiological $\mathrm{pH}$ and being capable of forming matrix are used for the formulation of sustained release SMEDDS $^{38}$. Ping Gao et al developed new supersaturable selfemulsifying drug delivery system of paclitaxel by using hydroxypropylmethyl cellulose (HPMC) polymer as a precipitation inhibitor with a conventional SEDDS formulation. In this study it has been observed that the supersaturated state is prolonged by use of HPMC in the formulation whereas in the absence of HPMC the SEDDS formulation undergoes rapid precipitation, yielding a low paclitaxel solution concentration. The results of pharamacokinetic study conducted in male Sprague-Dawley rats shows paclitaxel SEDDS formulation with HPMC (Supersaturable SEDDS) shows $\sim 10$-fold higher maximum concentration (Cmax) and five-fold higher oral bioavailability than that of Taxol and SEDDS without HPMC orally ${ }^{39}$.

Other components: Other components might be $\mathrm{pH}$ adjusters, flavors, and antioxidant agents. Indeed a characteristic of lipid products, particularly those with unsaturated lipids show peroxide formation with oxidation. Free radicals such as ROO., RO., and .OH can damage the drug and induce toxicity. Lipid peroxides may also be formed due to auto-oxidation, which increases with unsaturation level of the lipid molecule. Hydrolysis of the lipid may be accelerated due to the $\mathrm{pH}$ of the solution or from processing energy such as ultrasonic radiation. Lipophilic antioxidants (e.g. $\alpha$-tocopherol, propyl gallate, ascorbyl palmitate or BHT) may therefore be required to stabilize the oily content of the SMEDDS.

\section{FORMULATION OF SMEDDS}

The novel synthetic hydrophilic oils and surfactants usually dissolve hydrophobic drugs to a greater extent than conventional vegetable oils. The addition of solvents, such as ethanol, PG and PEG may also contribute to the improvement of drug solubility in the lipid vehicle ${ }^{45}$. With a large variety of liquid or waxy excipients available ranging from oils through lipids, hydrophobic and hydrophilic surfactant to water soluble co solvent, there are many different combinations that could be formulated for encapsulation in hard or soft gelatin or mixture which disperse to give fine colloidal emulsions ${ }^{22}$. The following should be considered in the formulation of a SMEDDS.

- The solubility of the drug in different oil, surfactants and co solvents

- The selection of oil, surfactant and co solvent based on the solubility of the drug

- Preparation of the phase diagram.

- The preparation of SMEDDS formulation by dissolving the drug in a mixture of oil, surfactant and co solvent ${ }^{46}$.

Ternary diagram: Pseudo ternary phase diagram is used to map the optimal composition range for three key excipients according to the resulting droplet size following selfemulsification, stability upon dilution and viscosity. Phase diagrams are useful tools to determine the number and types of phases, the wt $\%$ of each phase and the composition of each phase at a given temperature and composition of the system. These diagrams are threedimensional but are illustrated in two-dimensions for ease of drawing and interpretation.

Mechanism of self-emulsification: Self emulsification occurs, when the entropy change occurs, dispersion is greater than the energy required to increase the energy required to increase the surface area of the dispersion ${ }^{9}$. The free energy of conventional emulsion formation is a direct function of the energy required to create a new surface between the two phases and can be described by the equation.

\section{$\delta \mathrm{G}=\sum \mathrm{Ni} \pi$ ri $2 \sigma$}

Where:

$\delta G$ is the free energy associated with the process (ignoring the free energy of mixing),

$\mathrm{N}$ is the number of droplets of radius $\mathrm{r}$,

$\sigma$ is interfacial energy with time

The two phases of the emulsion will tend to separate, in order to reduce the interfacial area and subsequently, the free energy of the system. Therefore, the emulsions resulting from aqueous dilution are stabilized by conventional emulsifying agents, which form a monolayer around the emulsion droplets and hence, reduce the interfacial energy, as well as providing a barrier to coalescence $^{47}$. In case of self-emulsifying system, the free energy required to form the emulsion is either very low or positive or negative then, the emulsion process occurs spontaneously ${ }^{48}$. Emulsification require very little input energy, involves destabilization through contraction of local interfacial regions. For emulsification to occur, it is necessary for the interfacial structure to have no resistance to surface shearing ${ }^{30}$. In earlier work it was suggested that the case of emulsification could be associated with the ease by which water penetrates into the various liquid crystal or phases get formed on the surface of the droplet ${ }^{7}$. The addition of a binary mixture (oil/non-ionic surfactant) to the water results in the interface formation between the oil and aqueous continuous phases, followed by the solubilization of water within the oil phase owing to aqueous penetration through the interface, which occurs until the solubilization limit is reached close to the interface ${ }^{8}$. Further aqueous penetration will result in the formation of the dispersed liquid crystalline phase. As the aqueous penetration proceeds, eventually all materials close to the interface will be liquid crystal, the actual amount depending on the surfactant concentration in the binary mixture once formed, rapid penetration of water into the aqueous cores, aided by the gentle agitation of the self emulsification process causes interface disruption and droplet formation. A combination of particle size analysis and low frequency dielectric spectroscopy was used to examine self-emulsifying properties of a series of Imwitor 742 (a mixture of mono- 
and diglycerides of Caprylic acids/Tween 80) systems, which provided evidence that the formation of the emulsion may be associated with liquid crystal formation, although the relationship was clearly complex ${ }^{48}$. The presence of the drug may alter the emulsion characteristics, possibly by interacting with the liquid crystal phase. The droplet structure can pass from a reversed spherical droplet to a reversed rod-shaped droplet, hexagonal phase, lamellar phase, cubic phase or other structures until, after appropriate dilution, a spherical droplet will be formed again.

\section{CHARACTERIZATION OF SMEDDS}

- Particle size: The droplet size of the emulsion is a crucial factor because it determines the rate and extent of drug release as well as absorption. Photon correlation spectroscopy (PCS) is a useful method for determination of emulsion droplet size especially when the emulsion properties do not change upon infinite aqueous dilution, a necessary step in this method ${ }^{50}$.

- Polarity: Emulsion droplet polarity is also a very important factor in characterizing emulsification efficiency. The HLB, chain length, degree of unsaturation of the fatty acid, molecular weight of the hydrophilic portion and concentration of the emulsifier have an impact on the polarity of the oil droplets. Polarity represents the affinity of the drug compound for oil and/or water and the type of forces formed. Rapid release of the drug into the aqueous phase is promoted by polarity ${ }^{50}$.

- Zeta potential: The charge of the oil droplets in conventional SMEDDS is negative due to the presence of free fatty acids; however, incorporation of a cationic lipid, such as oleylamine at a concentration range of 1.0-3\%, will yield cationic SMEDDS. Thus, such systems have a positive $n$-potential value of about $35-45 \mathrm{mV}^{15}$. This positive $n$-potential value is preserved following the incorporation of the drug compounds.

- Drug precipitation /stability on dilution: The ability of SMEDDS to maintain the drug in solubilised form is greatly influenced by the solubility of the drug in oil phase. If the surfactant or co-surfactant is contributing to the greater extent in drug solubilisation then there could be a risk of precipitation, as dilution of SMEDDS will lead to lowering of solvent capacity of the surfactant or cosurfactant, hence it is very important to determine stability of the system after dilution. This is usually done by diluting a single dose of SMEDDS in $250 \mathrm{ml}$ of $0.1 \mathrm{~N} \mathrm{HCl}$ solution. This solution is observed for drug precipitation if any. Ideally SMEDDS should keep the drug solubilized for four to six hours assuming the gastric retention time of two hours.

\section{EVALUATION}

Thermodynamic stability studies: The physical stability of a lipid -based formulation is also crucial to its performance, which can be adversely affected by precipitation of the drug in the excipient matrix. In addition, poor formulation physical stability can lead to phase separation of the excipient, affecting not only formulation performance, but visual appearance as well. Furthermore, incompatibilities between the formulation and the gelatin capsules shell can lead to brittleness or deformation, delayed disintegration, or incomplete release of $\mathrm{drug}^{21}$.

- Heating Cooling Cycle: Six cycles between refrigerator temperature $\left(4^{\circ} \mathrm{C}\right)$ and $45^{\circ} \mathrm{C}$ with storage at each temperature of not less than $48 \mathrm{~h}$ is studied. Those formulations, which are stable at these temperatures, are subjected to centrifugation test.

- Centrifugation: Passed formulations are centrifuged thaw cycles between $21^{\circ} \mathrm{C}$ and $+25^{\circ} \mathrm{C}$ with storage at each temperature for not less than $48 \mathrm{~h}$ is done at 3500 rpm for $30 \mathrm{~min}$. Those formulations that does not show any phase separation are taken for the freeze thaw stress test.

- $\quad$ Freeze Thaw Cycle: Three freeze for the formulations. Those formulations passed this test showed good stability with no phase separation, creaming, or cracking.

Dispersibility test: The efficiency is assessed using a standard USP XXII dissolution apparatus 2. One $\mathrm{mL}$ of each formulation was added to $500 \mathrm{~mL}$ of water at $37 \pm 0.5$ ${ }^{\circ} \mathrm{C}$. A standard stainless steel dissolution paddle rotating at $50 \mathrm{rpm}$ provided gentle agitation. The in vitro performance of the formulations is visually assessed using the following grading system $^{21}$ :

Grade A: Rapidly forming (within $1 \mathrm{~min}$ ) nanoemulsion, having a clear or bluish appearance.

Grade B: Rapidly forming, slightly less clear emulsion, having a bluish white appearance.

Grade C: Fine milky emulsion that forms within $2 \mathrm{~min}$.

Grade D: Dull, grayish white emulsion having slightly oily appearance that is slow to emulsify (longer than $2 \mathrm{~min}$ ).

Grade E: Formulation, exhibiting either poor or minimal emulsification with large oil globules present on the surface.

Grade A and Grade B formulation will remain as nanoemulsion when dispersed in GIT. While formulation falling in Grade $\mathrm{C}$ could be recommend for SEDDS formulation.

Turbidimetric Evaluation: Nepheloturbidimetric evaluation is done to monitor growth of emulsification. Fixed quantity of Selfemulsifying system is added to fixed quantity of suitable medium $(0.1 \mathrm{~N}$ hydrochloric acid) under continuous stirring $(50 \mathrm{rpm})$ on magnetic plate at ambient temperature, and the increase in turbidity is measured using a turbidimeter. However, since the time required for complete emulsification is too short, it isn't possible to monitor the rate of change of turbidity (rate of emulsification) $)^{48}$.

Viscosity Determination: The SMEDDS system is generally administered in soft gelatin or hard gelatin capsules. So, it can be easily pourable into capsules and such system should not too thick to create a problem. The 
rheological properties of the micro emulsion are evaluated by Brookfield viscometer ${ }^{43}$.

Droplet Size Analysis Particle Size Measurements: The droplet size of the emulsions is determined by photon correlation spectroscopy (which analyses the fluctuations in light scattering due to Brownian motion of the particles) using a Zetasizer able to measure sizes between 10 and $5000 \mathrm{~nm}$. Light scattering is monitored at $25^{\circ} \mathrm{C}$ at a $90^{\circ}$ angle, after external standardization with spherical polystyrene beads ${ }^{43}$.

Refractive Index and Percent Transmittance: Refractive index and percent transmittance proved the transparency of formulation. The refractive index of the system is measured by refractometer by placing drop of solution on slide and it compare with water (Refractive index of water1.333). The percent transmittance of the system is measured at particular wavelength using UV-spectrophotometer keeping distilled water as blank. If refractive index of system is similar to the refractive index of water and formulation have percent transmittance $>99 \%$, then formulation has transparent nature.

Electro conductivity Study: The SEDD system contains ionic or non-ionic surfactant, oil, and water. So, this test is used to measure the electroconductive nature of system. The electro conductivity of resultant system is measured by electroconductometer.

In vitro Diffusion Study: In vitro diffusion studies are performed to study the release behavior of formulation from liquid crystalline phase around the droplet using dialysis technique ${ }^{43}$.

Drug content: Drug from pre-weighed SMEDDS is extracted by dissolving in suitable solvent. Drug content in the solvent extract was analyzed by suitable analytical method against the standard solvent solution of drug.

Droplet polarity: Droplet polarity and droplet size are important emulsion characteristics. Polarity of oil droplets is governed by the HLB value of oil, chain length and degree of unsaturation of the fatty acids, the molecular weight of the hydrophilic portion and concentration of the emulsifier. A combination of small droplets and their appropriate polarity (lower partition coefficient $\mathrm{o} / \mathrm{w}$ of the drug) permit acceptable rate of release of the drug. Polarity of the oil droplets is also estimated by the oil/water partition coefficient of the lipophillic drug ${ }^{9,38}$.

Sustained release: For this, dissolution study is carried out for SMEDDS. Drugs known to be insoluble at acidic $\mathrm{pH}$ can be made fully available when it is incorporated in SMEDDS $^{38}$.

Yield of the smedds: The SMEDDS formed is filtered from the solvent, dried in the desiccators and weighed to get the yield of the SMEDDS formulated per batch. Percentage yield can be calculated by formula ${ }^{48}$

$$
\% \text { recovery }=\mathrm{W} 1 / \mathrm{W} 2+\mathrm{W} 3 * 100
$$

Where, W1 is the weight of the SMEDDS formulated.

\section{W2 weight of the drug added.}

W3 is the weight of the lipid and surfactant used as the starting material.

The bioavailability of some of the poorly soluble drugs is enhanced by SMEEDS enlisted in Table 3 and examples of marketed SEDDS formulations are enlisted in Table 4.

Table: 3 Example of bioavailability enhancement of pooly soluble drug after administration of SMEDDS formulations ${ }^{51}$

\begin{tabular}{|l|l|}
\hline COMPOUND & OBSERVATIONN AFTER STUDY \\
\hline Win 54954 & $\begin{array}{l}\text { No difference in BA but improved reproducibility, increased C max } \\
\text { Increased BA and C max and reduced T max from SMEDDS } \\
\text { Increased Cmax, AUC and dose linearity and reduced food effect from SMEDDS } \\
\text { Reduced intra- and inter-subject variability from SMEDDS } \\
\text { Trend to higher BA from LCT SMEDDS }\end{array}$ \\
Halofantrine & BA increase of at least 10- fold from all lipid based formulations \\
Ontazolast & BA 1.5 fold higher from SMEDDS \\
Simvastatin & BA from LCT solution and LC-SMEDDS 7- fold and 6- fold higher than that from \\
Danazol & MC-SMEDDS \\
& BA 1.7-fold higher from SMEDDS \\
Carvediol Solvent green 3 & BA approximately 2-and 50- fold higher from SMEDDS \\
Silymarin & BA significantly increased from all SMEDDS \\
Atorvastatin & Increased BA and reduced food effect \\
Itraconazole & BA 3-fold higher from SMEDDS \\
Atovaquone & BA LC-SMEDDS=MC-SMEDDS \\
Seocalcitol &
\end{tabular}


Table 4: Examples of marketed SEDDS formulations ${ }^{52}$

\begin{tabular}{|c|c|c|c|c|}
\hline DRUG NAME & COMPOUND & DOSAGE FORM & COMPANY & INDICATION \\
\hline Neoral@ & Cyclosporine A/I & Soft gelatin capsule & Novartis & Immune suppressant \\
\hline Norvir & Ritonavir® & Soft gelatin capsule & Abbott Laboratories & HIV antiviral \\
\hline Fortovase® & Saquinavir & Soft gelatin capsule & Hoffmann-La Roche inc. & HIV antiviral \\
\hline Agenerase ${ }^{\circledR}$ & Amprenavir & Soft gelatin capsule & Glaxo Smithkline & HIV antiviral \\
\hline Targretin $\AA$ & Bexarotene & Soft gelatin capsule & Ligand & Antineoplastic \\
\hline Rocaltrol® & Calcitriol & Soft gelatin capsule & Roche & Calcium Regulator \\
\hline Convulex ${ }^{\circledR}$ & Valproic acid & Soft gelatin capsule & Pharmacia & Antiepileptic \\
\hline Lipirex® & Fenofibrate & Hard gelatin Capsule & Genus & Antihyperlipoproteinemic \\
\hline Sandimmune ® & Cyclosporine A/II & Soft gelatin capsule & Novartis & Immuno Suppressant \\
\hline Gengraf® & Cyclosporine A/III & Hard gelatin Capsule & Abbott Laboratories & Immuno Suppressant \\
\hline
\end{tabular}

\section{FACTORS AFFECTING SMEDDS}

Drug dose: Drugs, which are administered at very high dose, are not suitable for SMEDDS, unless they exhibit extremely good solubility in at least one of the components of SMEDDS, preferably lipophilic phase. The drugs exhibit limited solubility in water and lipids (typically $\log \mathrm{P}$ values of approximately 2) are most difficult to deliver by SMEDDS.

Drug solubility in oil phase: The ability of SMEDDS to maintain the drug in solubilised form is generally influenced by the solubility of the drug in oily phase. If the surfactant or co-surfactant is contributing to a greater extent of drug solubilization, then there could be a risk of precipitation, as dilution of SMEDDS will lead to lowering of solvent capacity of surfactant or co surfactant.

Equilibrium solubility measurement: It can be carried out to anticipate potential cases of precipitation in the gut. However, crystallization could be slow in solubilizing environment of the gut. Poutons study reveals that such formulation can take up to 5 days to reach equilibrium and that the drug can remain in a super saturated state up to 24 hours after the initial emulsification event ${ }^{9}$.

Polarity of lipid phase: The polarity of lipid phase is one of the factors that govern the release from the microemulsion. HLB, chain length and degree of unsaturation of fatty acid, molecular weight of the lipophilic portion and concentration of the emulsifier govern the polarity of droplets. In fact the polarity reflects the affinity of the drug for oil and /or water and the type of forces involved. The high polarity will promote rapid rate of release of the drug into the aqueous phase. This is conformed by the observation of Sang-Cheol et al. who observed that the rate of release of Idebenone from SMEDDS is dependent upon the polarity of oil phase used. The highest release was obtained with the formulation that had oily phase with highest polarity ${ }^{53}$.

Charge of emulsion droplets: Multiple physiological studies have proved that the apical potential of absorptive cells, as well as that of all other cells in the body, is negatively charged with respect to the mucosal solution in the lumen ${ }^{54}$. Gershanik and Benita have shown that positively charged emulsion droplets formed by adding oleylamine (OA) to appropriate SEDDS undergo electrostatic interaction with the CACO-2 monolayer and the mucosal surface of the everted rat intestine ${ }^{55}$. This formulation enhanced the oral bioavailability of progesterone in young rats. Benzoic acid had a dual function on the SEDDS; it could improve the selfemulsifying performance of self-emulsifying oily formulations (SEOFs) and self-microemulsifying oily formulations (SMEOFs) in $0.1 \mathrm{~N} \mathrm{HCl}$ due to formation of a positively charged emulsion ${ }^{56}$. SMEDDS designed for the oral delivery of lipophilic drugs are enlisted in Table 5.

Table 5: Examples of smedds designed for the oral delivery of lipophilic drugs ${ }^{57}$

\begin{tabular}{|l|l|l|l|l|l|l|}
\hline Delivery system & Oil & Surfactant & \% w/w & Solvent & Drug compound & $\begin{array}{l}\text { Drug } \\
\text { content }\end{array}$ \\
\hline SMEDDS & - & $\begin{array}{l}\text { Polyglycolized glycerides } \\
\text { (hlb:1-14) }\end{array}$ & 96 & - & Indomethacin & 4 \\
\hline $\begin{array}{l}\text { SMEDDS (sandimmun } \\
\text { neoral) }\end{array}$ & $\begin{array}{l}\text { Hydrolysed } \\
\text { Corn oil }\end{array}$ & $\begin{array}{l}\text { Polyglycolized glycerides, } \\
\text { POE-castor oil derivative }\end{array}$ & Na & Glycerol & Csa & 10 \\
\hline $\begin{array}{l}\text { Smedds } \\
\text { sandimmun neoral) }\end{array}$ & $\begin{array}{l}\text { Hydrolysed } \\
\text { Corn oil }\end{array}$ & $\begin{array}{l}\text { Polyglycolized glycerides, } \\
\text { POE-castor oil derivative }\end{array}$ & Na & Ethanol & CsA \\
\hline SMEDDS & $\begin{array}{l}\text { Triglyceride maisine 35- } \\
\text { ethanophore EL 58 } \\
5(111,1 m l, \text { Mlm) }\end{array}$ & Maisine 35-1, cremophor EL & 58 & Ethanol & Halofantrine & 5 \\
\hline SMEDDS & Glyceryl dioleate & Cremophor EL, PEG400 & $55-58$ & Ethanol & Paclitaxel( \pm CsA) & $5.7-6.25$ \\
\hline SMEDDS & Dl-alpha tocopherol & & 62 & Ethanol & Paclitaxel & 3 \\
\hline
\end{tabular}




\section{CONCLUSION}

Self-microemulsifying drug delivery systems are a promising approach for the formulation of drug compounds with poor aqueous solubility. The oral delivery of hydrophobic drugs can be made possible by SMEDDSs,

\section{REFERENCES}

1. Hou D Z, Xie C S, Huang K, Zhu, C H, The production and characteristics of solid lipid nanoparticles (SLN) Biomaterials, 2003, 24, 1781-1785.

2. Sarkar N N, Mifepristone: bioavailability, pharmacokinetics and usefuleffectiveness. European Journal Obstet Gynaecol. Reprod Biol, 2002, 101, 113-120.

3. Gao P, Guyton, M E, Huang T, Bauer J M, Stefanski K J, Lu Q, Enhanced oral bioavailability of a poorlywater soluble drug PNU91325 by supersaturable formulations, Drug Dev Ind Pharm, 2004, 30, 221-229.

4. You J, Cui F, Li Q, Han X, Yu Y, Yang M, A novel formulation design about water-insoluble oily drug: preparation of zedoaryl turmeric oil microspheres with self emulsifying ability and evaluation in rabbits, Int. J. Pharm, 2005, 288, 315-323.

5. Attama A A, Nkemnele M O, In vitro evaluation of drug release from self micro-emulsifying drug delivery systems using a biodegradable homolipid from Capra hircus, Int J Pharm, 2005, 304, 4-10.

6. Tang J, Self-Emulsifying Drug Delivery Systems: strategy for improving oral delivery of poorly soluble drugs, Cur Drug Th, 2007, 2, 85-93.

7. Wakerly M G, et al, Self-emulsification of veg: oil-non-ionic surfactant mixtures, ACS symp Ser, 1986, 311,242-255.

8. Wakerly M G, Pouton C W and Maekin B J, Evaluation of the self emulsifying performance of a non-ionic surfactant-vegetable oil mixture, J Pharma Pharmacol,1987, 39, 6P.

9. Pouton $\mathrm{C} \mathrm{W}$, Effects of the inclusion of a model drug on the performance of self-emulsifying formulations, J Pharma.Pharmacol, 1985, 37,1P.

10. Lin JH, Chen W, King J, The effect of dosage form on oral absorption of $\mathrm{L}-365,260$, a potent CCK receptor antagonist in dogs, Pharm Res, 1991, 8, 272.

11. Groves MJ, Degalindez DA, The self-emulsifying action of mixed surfactants in oil, Acta Pharm Suec, 13, 1976, 361- 372.

12. McClintic JR, Physiology of the Human Body, Wiley, New York, 1976, (2), 189.

13. Kommuru $\mathrm{T}$ R, Gurley B, Khan $\mathrm{M}$ A and Reddy I K, Selfemulsifying drug delivery systems (SEDDS) of coenzyme Q10: formulation development and bioavailability assessment, Int J Pharm 2005, 212, 233,246.

14. Julianto T, Yuen K H and Noor A M, Improved bioavailability of vitamin $\mathrm{E}$ with a self-emulsifying formulation, Int J Pharm, 2000, 200, 53,57.

15. Khoo S M, Humberstone A J, Porter C J H, Edwards G A and Charman W N, Formulation design and bioavailability assessment of lipidic self-emulsifying formulations of halofantrine, Int $\mathbf{J}$ Pharm, 1998, 167, 155,164,624.

16. Gao Z G, Choi H G, Shin H J, Park K M, Lim S J, Hwang K J, and $\mathrm{Kim} \mathrm{C} \mathrm{K}$, Physicochemical characterization and evaluation of a micro emulsion system for oral delivery of cyclosporine A, Int $\mathrm{J}$ Pharm, 1998, 161, 75,86.

17. Bhattacharya D K, Oil Seeds and Fats In: Bringi, NV (Ed), Nontraditional Oil seeds and Oils of India, Oxford and IBH Publishing Co Pvt Ltd, New Delhi, 1987, 73-117.

18. Amidon $\mathrm{G}$, e.al, A theoretical basis for a biopharmaceutic drug classification: the correlation of in vitro drug product dissolution and in vivo bioavailability, Pharm.Res. 1995, 12, 413-420.

19. Kawakami K, Yoshikawa T, Moroto Y, Kanakao E, Takahuani K, Nishihara $\mathrm{Y}$ and Masuda K. Microemulsion formulation for enhanced absorption of poorly soluble Drugs I Prescription design, J of Contr Rel, 2002, 81, 75-82. which have been shown to substantially improve oral bioavailability and thus the dose of the drug can be reduced. With future development of this technology, SMEDDSs will continue to enable novel applications in drug delivery and solve problems associated with the delivery of poorly soluble

drugs.

20. Cortesi R, Espositi E, Maietti A, Menegatti E and Nastruzzi C, Formulation study for the antitumor drug camptothecin: liposomes, micellar solutions and a microemulsion, Int $\mathbf{J}$ of Pharm, 1997, 159, 95-103.

21. P P Constantinides, Lipid microemulsions for improving drug dissolution and oral absorption: physical and biopharmaceutical aspects, Pharm. Res, 1995, 12, 1561-72.

22. N Farah, J P Laforet and J Denis, Self Micro Emulsifying Drug Delivery Systems for improving dissolution of drugs: In vitro evaluations, presented by Gattefosse Patented Technology at the AAPS Annual Meeting in San Diego, November 1994.

23. Jessy Shaji and vishvesh Joshi India Pharmaceutical Journal Selfmicro Emulsifying drug delivery system for improving bioavability of hydrophobic Drug and its Potential to give Sustain Release dosage form.

24. Lawrence MJ, Rees GD, Microemulsion-based media as novel drug delivery system, Advanced Drug Delivery Review, 2000, 45, 89-121.

25. Weiner M, B ernstin IL Advance Reaction to drug formulation Agents New York; Marcel Dekker, Inc, 1989.

26. H Shen and M Zhong, Preparation and evaluation of self-micro emulsifying drug delivery system containing atorvastatin, Journal of Pharmacy and Pharmacology, 2006, 58, 1183-1191.

27. Tuleu C, Newton M, Rose J, et al, Comparative bioavailability study in dogs of a selfemulsifying formulation of progesterone presented in a pellet and liquid form compared with an aqueous suspension of progesterone, J Pham Sci, 2004, 93, 495-502.

28. Ritesh B Patel et al, Self Emulsifying Drug Delivery System, pharmtech.com, 2008.

29. Kimura M, Shizuki M, Miyoshi K, Sakai T, Hidaka H, Takamura $\mathrm{H}$, Matoba T, Relationship between the molecular structures and emulsification properties of edible oils, Biotechnology Biochemistry, 1994, 58, 1258-61.

30. Tolle S, Zuberi T, Lawrence MJ, Physiochemical and dersolubilisation properties of $\mathrm{N}, \mathrm{N}$-dimethyl-N-(3-dodecyloxy propyl) amine oxide: a biodegradable nonionic surfactant, Journal of Pharmaceutical Science, 2000, 89, 798-806.

31. N H Shah et al, Self-emulsifying drug delivery systems (SEDDS) with polyglycolized glycerides for improving in vitro dissolution and oral absorption of lipophilic drugs, Int. J Pharm, 1994, 106, 15-23.

32. Hauss DJ, Fogal SE, Ficorilli JV, Price CA, Roy T, Jayaraj AA, Keirns JJ, Lipid-based delivery systems for improving the bioavailability and lymphatic transport of a poorly water-soluble LTB4 inhibitor, Journal of Pharmaceutical Science, 1998, 87, 164 169.

33. Georgakopoulos E, Farah N, Vergnault G, Oral anhydrous nonionic microemulsions administered in softgel capsules B T Gattefosse, 1992, 85, 11-20.

34. Swenson ES, Milisen WB, Curatolo W, Intestinal permeability enhancement: efficacy, acute local toxicity and reversibility, Pharmacy Research, 1994, 11, 1132-42.

35. Serajuddin AT, Shee PC, Mufson D, Bernstein DF, Augustine MA, Effect of vehicle amphiphilicity on the dissolution and bioavailability of a poorly water-soluble drug from solid dispersion, Journal of Pharmaceutical Science, 1988, 77, 414-417.

36. Chen et al, Oral dosage self emulsifying formulations of pyranone protease inhibitors, United States Patent 6,555,558, April 29, 2003. 
37. Mahesh V Patel, Feng Jing Chen, Compositions and methods for improved delivery of hydrophobic agents, United States Patent 6451339, 2002.

38. Philippe Barthelemy, Hassan Benameur, Composition with sustained release of active principle capable of forming microemulsion, united state patent 6309665, 2001.

39. Ping Gao, Bobby D Rush, William P Pfund, Tiehua Huang, Juliane M, Bauer, Walter Morozowich, Ming- Shang Kuo, Michael J Hageman, Development of a supersaturable SEDDS (SSEDDS) formulation of paclitaxel with improved oral bioavailability, J Pharm Sci, Vol 92, Issue 12, 2386-2398 2003.

40. Nazzal S, Nutan M, Palamakula A, Shah R, Zaghloul AA, Khan MA, Optimization of self-nanoemulsified tablet dosage form of ubiquinone using response surface methodology: effect of formulation ingredients, Int J Pharm, 2002, 240, 103-114.

41. Booth SW, Clarke A, Newton JM, Inventors, Spheronized selfemulsifying system for hydrophobic and water sensitive agents, US patent 6630150, October 7, 2003.

42. SchwarzJ, inventor, Solid self emulsifying dosage form for improved delivery of poorly soluble hydrophobic compounds and the process of preparation thereof, US patent application 20030072798, April 17, 2003.

43. Patil P, Joshi P, Paradkar A, Effect of formulation variables on preparation and evaluation of gelled selfemulsifying drug delivery system (SEDDS) of ketoprofen, AAPS Pharm SciTech, 2004, 5, E42.

44. Patil P, Paradkar A, Porous Polystyrene Beads as Carriers for Self-Emulsifying System Containing Loratadine AAPS Pharm SciTech, 2006, 7, E1

45. J R Crison and G L Amidon, Method and formulation for increasing the bioavailability of poorly water-soluble drugs, US Patent No 5,993,858, issued November 30, 1999.

46. Nazzal and M.A. Khan, Controlled release of a self-emulsifying formulation from a tablet dosage form: Stability assessment and optimization of some processing parameters, International Journal of Pharmaceutics, 2006, 315,110-121.

47. Reiss H, Entropy induced dispersion of bulk liquids, J Colloids Interface Science, 1975, 53, 61-70.
48. Craig DQM, Lievens HSR, Pitt KG, Storey DE, An investigation into the physico-chemical properties of self-emulsifying systems using low frequency dielectric spectroscopy, surface tension measurements and article size analysis, Int J Pharm, 1993, 96, 147-155.

49. Dabros T, Yeung A, Masliyah J, Czarnecki, J Emulsification through area contraction, J Colloids, Interface science, 1999, 210, 222-224.

50. Charman WN, Noguchi T, Stella VJ, An experimental system designed to study the in situ intestinal lymphatic transport of lipophilic drugs in anesthetized rats, International Journal of Pharmacy, 1986, 33, 155-164.

51. P A Patel et al, Self Emulsifying Drug Delivery System: A Review, Research J Pharm and Tech, Oct-Dec 2008, 1(4).

52. Shukla et al, Self micro emulsifying drug delivery system, International Journal of Pharmaceutical Sciences, 2002, Vol-1, Issue- 2 .

53. Ho-Jin Kim, Kyung Ae Yoon, Mikyoung Hahn, Eunseok Park, and Sang-Cheol Chi, Preparation and in-vitro evaluation of self micro emulsifying drug delivery systems containing idebenone, Drug Dev Ind Pharm 2000, 26(5), 523-529.

54. Agust B J, Rogers N J, and Shefter E, Comparison of nasal, rectal, sublingual and intramuscular insulin efficiency and the effects of a bile salt absorption promoter, Journal of Pharmacology and Experimental Therapeutics, 1987, 244(1), 23-27.

55. Gershanik $\mathrm{T}$, Benzeno $\mathrm{S}$, Benita $\mathrm{S}$, Interaction of a selfemulsifying lipid drug delivery system with the everted rat intestinal mucosa as a function of droplet size and surface charge, Pharmaceutical Research, 1998, 15(6), 863-869.

56. Lanlan Wei, Peinan Sun, Shufang Nie, and Weisan Pan. Preparation and evaluation of SEDDS and SMEDDS containing Carvedilol, Drug Development and Industrial Pharmacy, 2005, 31, 785-794.

57. Anand U Kyatanwar et al, Self micro-emulsifying drug delivery system (SMEDDS) : Review, Journal of Pharmacy Research, 2010 ,

58. 